\title{
ESTIMATION OF THE DEFECT HAZARD CLASS IN BUILDING STRUCTURES: A DECISION SUPPORT SYSTEM
}

\author{
Vladislav A. Kats, L yubov A. Adamtsevich \\ National Research M oscow State University of Civil Engineering, M oscow, RUSSIA
}

\begin{abstract}
Technical condition monitoring of building structures located on hazardous facilities is a necessary requirement for their sustainable functioning. In this regard, the problem of development intellectual monitoring systems that allow to detect and classify operating defects by the hazardous level becomes very urgent. The study presents an approach of building decision support system (DSS) for detecting defects in building structures and estimation of their hazard class. Proposed approach is based on multi-criteria assessment of consecutive measurements acquired by acoustic emission method. A distinctive characteristic of the proposed approach is the ability to take into account the evolution of defects by mapping each AE time-series to diagnostic features matrix and analysing these matrices in sliding windows with overlay. Each matrix is validated by two criteria that form the necessary and sufficient conditions of the existence the evolving defects in building structure. They include the criterion for changing the number of clusters and the criterion for changing the acoustic emission activity. Proposed method was verified on the experimental data acquired from the technical condition monitoring of the vertical oil tanks. The results obtained from the experiment confirm the proposal that this approach can be utilized for effectively solving the problem of conditional monitoring of building structures located on the hazardous facilities allowing to detect and classify defects by their hazardous level.
\end{abstract}

Keywords decision support system, acoustic emission, feature extraction, clustering, defect hazard class estimation, image processing, distance transform.

\section{СИСТЕМА ПОДДЕРЖКИ ПРИНЯТИЯ РЕШЕНИЙ ДЛЯ ОЦЕНКИ КЛАССА ОПАСНОСТИ ДЕФЕКТОВ СТРОИТЕЛЬНЫХ КОНСТРУКЦИЙ}

\begin{abstract}
В.А. Кац, Л.А. Адамцевич
Национальный исследовательский Московский государственный строительный университет, Москва, РОССИЯ

Аннотация. Осуществление мониторинга технического состояний строительных конструкций, расположенных на опасных производственных объектах, является необходимым требованием для их устойчивой и непрерывной работы. В этой связи актуальной проблемой становится разработка интеллектуальных систем мониторинга, способных осуществлять детектирование и классификацию эксплуатационных дефектов конструкций по классам опасности. В работе представлен метод построения системы поддержки принятия решений (СППР), позволяющий классифицировать дефекты по степени опасности, основанный на многокритериальной оценке последовательных измерений данных, полученных методом акустической эмиссии. Отличительной характеристикой предложенного метода является способность учитывать эволюцию дефектов посредством расчета матриц диагностических признаков от исходных временных рядов акустической эмиссии в скользящем временном окне с перекрытием. Каждая матрица диагностических признаков проверяется двумя критериями, которые формируют необходимые и достаточные условия существования эксплуатационных дефектов в строительных конструкциях, а именно, критерий изменения количества кластеров и критерий изменения активности акустической эмиссии. Валидация указанного подхода произведена на экспериментальных данных, полученных в результате мониторинга технического состояния вертикальных нефтяных резервуаров. Результаты, полученные в ходе эксперимента, подтверждают предположение о том, что предложенный метод может быть использован для эффективного решения проблемы мониторинга технического состояния строительных конструкций, расположенных на опасных объектах, позволяющих обнаруживать и классифицировать дефекты по их степени опасности.
\end{abstract}

Ключевые слова: система поддержки принятия решений, акустическая эмиссия, методы извлечения диагностических признаков, оценка класса опасности, обработка изображений. 


\section{INTRODUCTION}

Continuous evaluation of the technical condition of building structures located on hazardous facilities is critically important for providing their smooth and trouble-free operation. One of the perspective method of conducting periodic conditional monitoring is an acoustic emission method (AE) [1]. It is a common knowledge that the acoustic emission signal emits in the material under the process of its deformation or destruction. Meanwhile, the $A E$ signal parameters correlate with evolution dynamics of the defects that are developing during the operation of the facility [2]. In this regard, the problem of developing a decision support system (DSS) based on AE data, which allows identifying the appearance of operating defects in the structure of the construction material in real time and classifying defects by hazard classes, seems urgent. According to the regulatory document [3], the condition of the defect can be described by one of the four hazard classes:

1) The I class source corresponds to nonhazardous defect

2) The II class source is an evolving defect, moderately hazardous.

3) The III class source corresponds to critically hazardous evolving defect

4) The IV class source is catastrophically hazardous defect.

Common systems of $\mathrm{AE}$ data processing are primarily based on the analysis of integral parameters of $A E$ flow such as mean or peak amplitude, the oscillation number, signal duration, MARSE (the area under the AE signal envelope higher than the amplitude discrimination threshold) and are suitable in the conditions of threshold data acquisition. Such approaches also include the wavelet-analysis of AE data [4]. These methods have weak noise immunity and which leads to their low efficiency under the signal-to-noise ratio $(S N R)<1$.

A uthors of paper [5] propose to estimate the hazard class of the defect by utilizing k-means algorithm. One of the main disadvantage of this method is the requirement of determining the number of clusters before the calculation. Furthermore, this approach based on the estimation of the data of current measurement and as a result, it does not consider the evolution of the defect.

The authors of the approach described in the article [6] propose to calculate periodic statistics on a set of integral time and frequency diagnostic parameters, such as amplitude, duration, energy, signal rise time, average frequency, peak power, etc. By the calculated statistics they determine and measure the distances between two classes, one of which is a reference (its characteristics obtained during pilot operation), and the other corresponds to monitoring data [6]. This approach is the most promising of presented, as it allows detecting defect in the controlled facility. Nevertheless, the main draw back of the method proposed in paper is that the comparison between the two classes by calculating distance metrics does not allow to determine the hazard class of the defect.

This study presents an innovative approach of building an effective decision support system that provides reliable detection of evolving defects. Within the framework of the approach, we describe a method that allows detecting the moments of transition of operational defects arising in the construction facility to the stage of a hazardous developing defect and a critically hazardous devel oping defect.

It is further noted that proposed method is an integral part of a comprehensive methodology for developing a decision support system for detecting operational defects in construction structures and assessing their hazard class. Other aspects of the implementation of the methodology related to algorithms for preprocessing measurement data, methods for extracting diagnostic features and reducing the dimension of the feature space, as well as training DSS, are described in $[7,8]$.

\section{METHODS}

The proposed method of the defect's hazard class determination is based on a multi-criteria 
assessment of diagnostic features extracted from acoustic emission time series, which are acquired during the non-destructive testing. This assessment is a combination of necessary and sufficient conditions, the simultaneous satisfaction of which allows to detect a defect in the structure and to determine its hazard class. A distinctive characteristic of the proposed method is the ability to take into account the evolution of defects over time by analyzing their diagnostic features, which are calculated in the sliding time-domain windows [8]. M eanwhile, the analysis of multiple consecutive measurements data collected within different intervals of time provides trends identification in diagnostic feature values changes.

In order to improve the accuracy of detecting developing defects in conditions of random nonstationary noise, we also propose an original algorithm based on processing a series of measurements by means of a multi-criteria assessment of the defect hazard class.

Figures/Tables should be centred within the page width and numbered sequentially. Figures/Tables should be numbered separately. M ultiple figures should be referred

using letters (e.g. Fig. 1a or 1b).

A set of $k$ consecutive measurements of a given length forms a series of measurements. The measurements are grouped in series by applying a sliding window with overlap. A ccordingly, the series is formed from $\mathrm{k}$ - 1 measurements related to the previous series, and one new measurement. Each series consists of a set of diagnostic feature matrices, which represent statistical parameters of acoustic emission time series obtained during preprocessing [9] and the feature extraction procedure [7]. This approach allows to ensure resistance to possible prolonged non-stationary interference and thereby protecting against false alarms of the DSS.

The proposed method for identifying the evolution of the hazard class of a defect in the object of control is based on two criteria:

1) Necessary - a criterion of clusters number changing that corresponds to defects with different hazard classes.
2) Sufficient - a criterion for the activity of acoustic emission, determined by the results of detecting anomalies in the diagnostic feature space.

Let $\xi_{i}$ - diagnostic feature matrix of $i$-th measurement, while $k$ - the number of measurements forming a series. Then $S_{j}=$ $\left\{\xi_{i-k} \ldots \xi_{i}\right\}$ is a diagnostic feature series per time interval $(i-k ; i)$. Consider two cases.

1) The defect is initially absent or is not in evolving condition (I-class).

Then the necessary condition of existence of the hazardous evolving defect in the inspecting structure is:

$\forall \xi_{i} \in S_{j}\left(\operatorname{Nclust}\left(\xi_{i}\right)>1\right) \wedge\left(\operatorname{Nclust}\left(\xi_{i}\right)>\right.$

$\left.\operatorname{Nclust}\left(\xi_{i-k}\right) \ldots \operatorname{Nclust}\left(\xi_{i-1}\right)\right)$

where $\operatorname{Nclust}\left(\xi_{i}\right)$ - the number of clusters calculated from diagnostic feature matrix $\xi_{i}$ of $\mathrm{i}$ -th measurement. This condition should fulfil for any matrices of diagnostic features, collected during measurements $i-k \ldots i$. The method of cluster number estimation will be considered further in this paper.

We formulate the sufficient condition as follows:

$$
\forall \xi_{i} \in S_{j} A_{\min }<A\left(\xi_{i}\right)<A_{\max }
$$

where $A\left(\xi_{i}\right)$ - activity coefficient of measurement i, $A_{\text {min }}$ - the threshold value of activity coefficient for moderately hazardous defect, $A_{\max }$ - the threshold of the activity coefficient for the critically hazardous defect.

2) The defect initially exists and corresponds to moderately hazardous evolving defect (II-class). Then the necessary condition of the defect transition to a critically hazardous class is:

$\forall \xi_{i} \in S_{j}\left(\operatorname{Nclust}\left(\xi_{i}\right)>2\right) \wedge\left(\operatorname{Nclust}\left(\xi_{i}\right)>\right.$
$\left.\operatorname{Nclust}\left(\xi_{i-k}\right) \ldots \operatorname{Nclust}\left(\xi_{i-1}\right)\right)$

while the sufficient condition is formulated as follows: 


$$
\forall \xi_{i} \in S_{j} A\left(\xi_{i}\right)>A_{\max }
$$

Now we consider the methods of criteria values calculation $\operatorname{Nclust}\left(\xi_{i}\right), A\left(\xi_{i}\right)$ and in detail.

\subsection{The method calculation the cluster number $\operatorname{Nclust}\left(\xi_{i}\right)$.}

Determining the hazard class of a defect requires studying the data on the evolution of $A E$ diagnostic features. $A E$ events obtained from a defect of the same hazard class form a cluster. $M$ eanwhile, the number of clusters increases when the defect hazard class changes [7]. Based on this statement, in formulas (1), (3), we formualte a criterion of changing the number of clusters by comparing the number of clusters in diagnostic feature matrices of a sequential set of measurements (series). There are several ways to determine the number of clusters $\operatorname{Nclust}\left(\xi_{i}\right)$. M ost of them are related to the calculation of metrics based on intracluster and intercluster distances in the space of diagnostic features, in particular the criterion of Calinski-Harabasz, Davies-Bouldin and Silhouette [10]. However, these criteria often lead to erroneous results, especially for convex clusters. Recently, there has been a growing interest in approaches based on visual assessment of clusters [11]. By translating the unmarked data into an image of $n$ $x \mathrm{n}$ size, where the objects are ordered in such a way as to simplify the identification of a potential cluster structure in the data. $M$ eanwhile, each pixel in the image corresponds to the degree of difference between pairs of objects [11]. This image highlights potential clusters as "dark blocks" along the diagonal axis of the image, corresponding to sets of objects with a low degree of difference.

As part of this paper, we propose a modified algorithm for determining the number of clusters based on the clustering visual representation algorithm (VAT) [11]. The VAT algorithm maps the difference matrix $D$ as a grayscale image, each element of which corresponds to the value of the difference metric $d_{i j}$ between objects $q$ and. At the same time, if the object $q$ belongs to a certain cluster, then it is a part of a submatrix with small values of the difference metric, i.e. it belongs to one of the "dark blocks" on the diagonal of the corresponding image. We propose to determine the number of "dark blocks" as follows:

1) Segmentation of the matrix image $D$

Due to the fact that information about the cluster data structure is displayed in the dark blocks of the difference matrix image, an important step of the algorithm is threshold image processing. The histogram of the matrix D has multiple modes, meanwhile the first mode corresponds to the average value of intracluster distances.

In order to identify the binarization threshold we utilize a combination of Otsu algorithms. The Otsu algorithm maximizes the intercluster variance. It is based on the assumption that all pixels on the image belong to two classes. However, the image of the difference matrix D contains blurred boundaries of dark blocks. In such case the algorithm cannot correctly identify the threshold value. To identify and suppress noise objects in the image, we propose to use the multi-threshold Otsu method [12]. After noise objects are suppressed, the standard image binarization method is used, which converts the original image to a binary one, where the pixel value on the image is equal to 1 , if it is greater than the threshold in grayscale, otherwise it is equal to 0 .

2) Projecting the image onto the main diagonal

In order to obtain a more informative image that allows to clearly distinguish the structure of the "dark blocks", it is necessary to consider the pixel values along the main diagonal of the image. As part of this work, it is proposed to project an image onto the main diagonal by summing the pixel intensity values along the diagonal of the image. However, the original binary image may have residual noise. In order to minimize the effect of residual noise on the result of counting the number of clusters, it is necessary to convert the binary image obtained in the previous step into such a representation that the value of each pixel of the resulting image is the distance from this pixel to the nearest non-zero pixels in the binary image. This representation is called Distance Transform 
[13]. The conversion of distances together with the projection on the main diagonal gives a more visual representation of the VAT image and allows to translate it into a one-dimensional signal. Thus, it is possible to define the number of clusters as the number of peaks on a one-dimensional signal.

3) Determination of the number of peaks on a one-dimensional diagonal projection signal

In this paper, we propose to utilize a first-order derivative to detect peaks in the signal. However, this approach should be used in combination with smoothing methods in order to reduce the likelihood of false positives. There are several ways to smooth the original signal. One of the most frequently used is the moving average [13]. Its main disadvantage is that averaging can lead to significant losses in the informative component of the original signal, which in turn will not allow to identify the appearance of a new cluster that corresponds to an evolving defect. In this paper, we propose to utilize a linear interpolation between the local maxima of the original signal. This method allows reaching required level of smoothing without losses in the informative component of original signal.

\subsection{The method of calculation the activity coefficient $A\left(\xi_{i}\right)$}

The acoustic emission activity coefficient [14] allows to determine the presence of long-term trends in acoustic emission data. Therefore, it can serve as a criterion for detecting defects. The activity coefficient is calculated based on the results of the anomaly detection method proposed in [8], which consists in determining the optimal position of the separating hyperplane between "normal" events and "anomalies". In the context of this work, abnormal events include AE signals emitted by defects of hazard classes II and III during monitoring. Normal events include hazard class I events, as well as various types of interference detected during pilot operation. In current paper, we propose to define the activity coefficient as the ratio of the number of abnormal events to the total number of $A E$ events received per unit of time.
Comparison of the activity coefficient with the reference threshold values allows us to determine the moment of transition of the object to hazard classes II and III (2), (4). The threshold values for defects of class II and III are specific for each construction facility and require clarification at the stage of pilot operation.

\section{RESULTS AND DISCUSSION}

Fig. 1 demonstrates the fragments of experimental $A E$ time series obtained during the non-destructive testing of oil reservoir located in Norilsk. We can see from the fig. 1 that the amplitude of $A E$ signals increase with the growth of the hazard class. The data acquisition was conducted by the means of non-threshold $A E$ collection method and the AE sensors with the sampling frequency of $2.5 \mathrm{MHz}$. The preliminary processing was carried out by extracting diagnostic features utilizing method proposed in [7]. A set of calculated diagnostic feature matrices applied further for this research and was a source data for the verification of the methods proposed in current paper.

Fig. 2(a, b) contain the comparison of proposed criterion of cluster number determination with the known criterion Davies-Bouldin, based on intracluster distances calculation. Fig. 2b demonstrates computation graphs of optimal cluster number via Davies-Bouldin criterion utilizing three methods of cluster analysis: kmeans, hierarchical clustering and Gaussian mixture distribution. The figure shows that the quality of the results of the proposed method does not depend on the type of clustering algorithm, it is based on image analysis of the cluster data structure, while the Davis-Boldin index changes significantly when using various methods of cluster analysis. The effectiveness of the proposed criterion for evaluating cluster changes was confirmed by the presence of peaks on the first-order derivative of the one-dimensional image projection of cluster structure in Fig. 2a. Thus, the proposed criterion has the high sensitivity to detecting the moments of occurrence of evolving defects. 
Estimation of the Defect Hazard Class in Building Structures: a Decision Support System

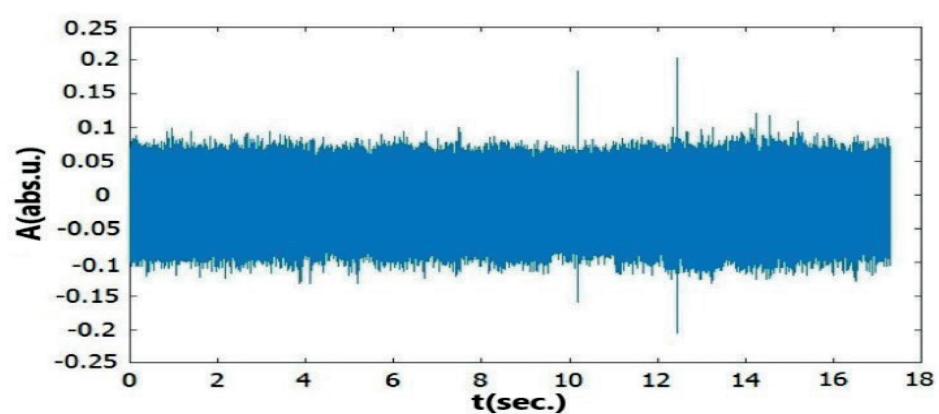

a)

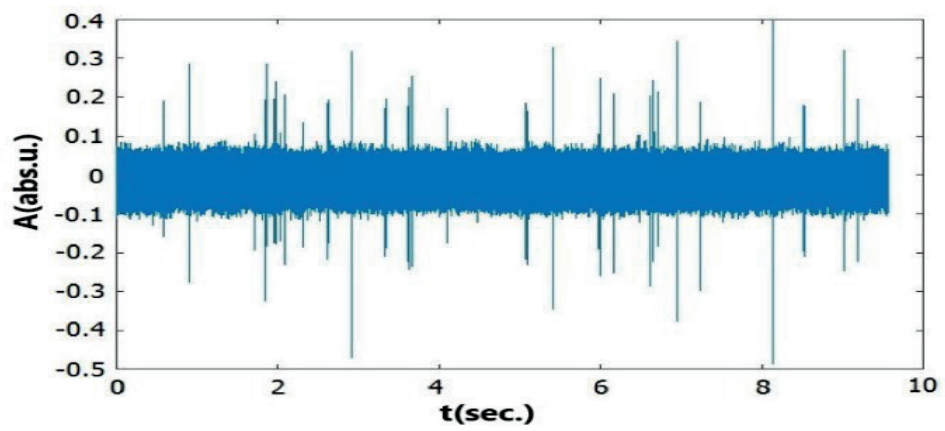

b)

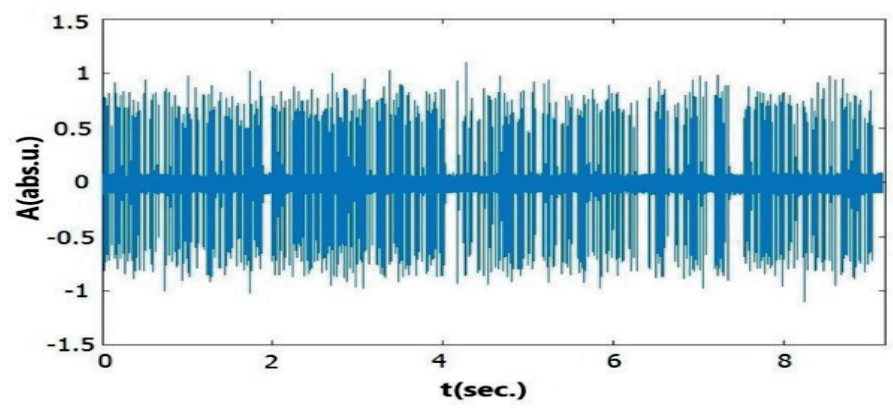

C)

Figure 1. a) the defect of the I hazard class, b) the defect of the II hazard class,

c) the defect of the III hazard class

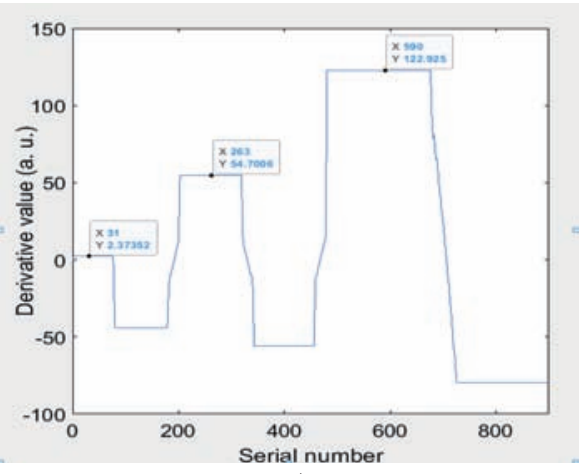

a)

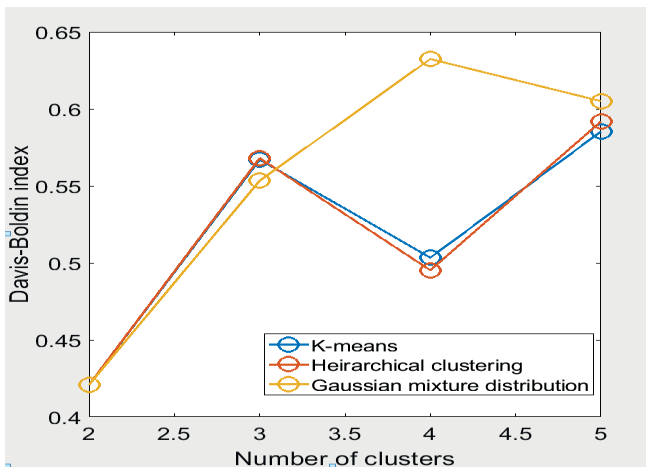

b)

Figure 2. Comparison of the proposed modification of VAT method with Davies-Bouldin index. a) First-order derivative of VAT image diagonal projection b) Davis-Bouldin optimization results based on various clustering methodsa) the defect of the I hazard class, b) the defect of the II hazard class, c) the defect of the III hazard class 
Fig. 3 shows the results of calculating the proposed criterion for changing the activity coefficient of acoustic emission. It follows from the figure that at the moment of defect state transition to a higher hazard class, the activity of acoustic emission increases significantly. In the intervals between the transition moments, the activity coefficient fluctuates around the average value with a small variance. The level of threshold values was chosen based on the median value of the activity coefficient for defects of the second and third hazard classes identified during pilot operation. For the second hazard class, the threshold value was 0.01 , for the third -0.27

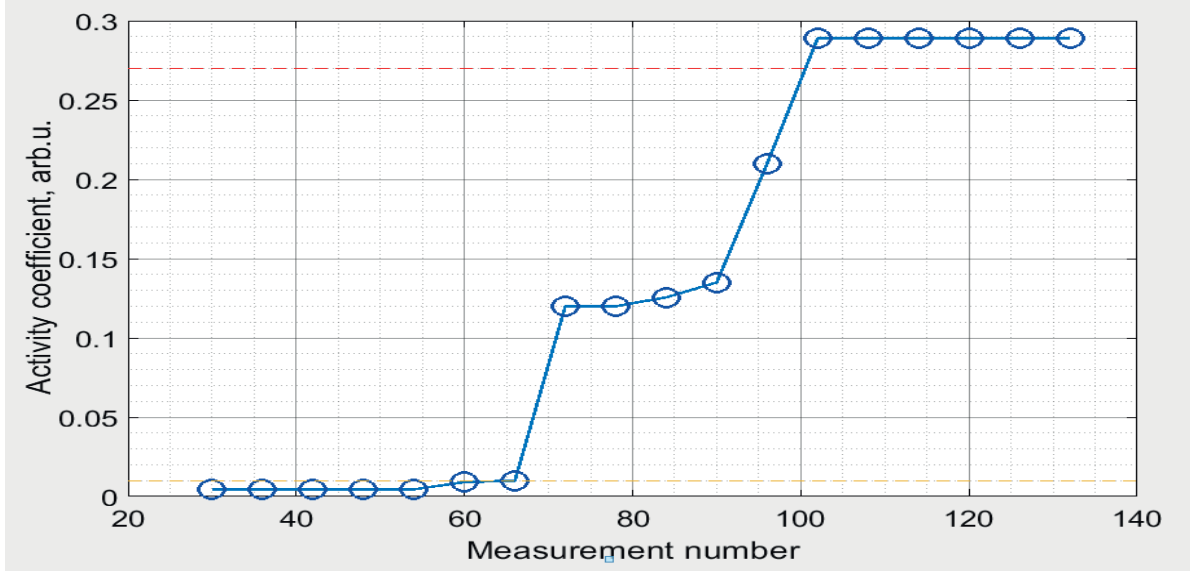

Figure 3. Comparison of the proposed modification of VAT method with Davies-Bouldin index

\section{CONCLUSION}

1) The paper presented an approach for developing a DSS that identifies the defect and determines its hazard class based on a multicriteria assessment of diagnostic features extracted from the acoustic emission time series that are obtained during the diagnostics of construction structures.

2) We propose to utilize a set of two criteria that form the necessary and sufficient conditions under which it is possible to detect moderately hazardous and critically hazardous evolving defects in the construction facilities. They include a criterion for changing the number of clusters and a criterion for changing the acoustic emission activity.

3) We described the original method of applying the proposed criteria, which is based on the process of grouping single consecutive measurements in a series by using a sliding window with overlaps. The proposed approach provides protection against false positives in the presence of stationary long-term noise of various nature occurring during the condition monitoring.

4) The verification of the proposed method was conducted on real construction of oil and gas facilities - vertical steel tank containing a defective weld.

5) Based on a numerical comparison of the results with prior known defects hazard classes it was verified that the proposed method allows to effectively determine the hazard class of evolving defects in construction facilities and detect the processes of their evolution.

\section{ACKNOWLEDGMENTS}

The reported study was funded by RFBR according to the research project № 20-3790089. A uthors thank companies Strategia NK $L t d$. and Diaform $L t d$. for the help in conducting acoustic emission diagnostics on the controlled facility. 


\section{REFERENCES}

1. Verstrynge E. A review on acoustic emission monitoring for damage detection in masonry structures. Construction and Building M aterials, 268, 121089 (2021).

2. Gholizadeh S, Baharudin, B. A review of the application of acoustic emission technique in engineering. Structural Engineering \& Mechanics, 54, 1075-1095 (2015).

3. GOST R 52727-2007. Technical diagnostics. A coustic-emission diagnostics. General requirements, 16 (2007).

4. Agletdinov E., M erson D., Vinogradov A. A new method of low amplitude signal detection and its application in acoustic emission. A pplied Sciences, 10, 73 (2020).

5. Pomponi E.; Vinogradov A. A real-time approach to acoustic emission clustering. Mech. Syst. Sig. Process. 40, 791-804 (2013).

6. Kattis S. Noesis-A dvanced Data A nalysis, Pattern Recognition \& Neural Networks Software for Acoustic Emission Applications. Kolloquium Schallemission, Statusberichte zur Entwicklung und A nwendung der Schallemissionsanalyse, 910 (2017).

7. Kats V., Volkov A. Features extraction from non-destructive testing data in cyberphysical monitoring system of construction facilities. Journal of Physics: Conference Series, 1425, 012149 (2019)

8. Kats V. Structural health monitoring system of construction facilities: enhanced training approach. Journal of Physics: Conference Series, 1694(1) (2020)

9. Giannakopoulos T., Pikrakis A. Introduction to Audio Analysis - A MATLAB Approach. Elsevier Ltd., 262 (2014).

10. Wang $\mathbf{X u}, \mathbf{Y}$ usheng $\mathbf{X} \mathbf{u}$. An improved index for clustering validation based on Silhouette index and Calinski-Harabasz index. IOP Conference Series: Materials Science and Engineering, 569(5) (2019).
11. K umar D., J ames C . V isual approaches for exploratory data analysis: A survey of the visual assessment of clustering tendency (vat) family of algorithms. IEEE Systems, $\mathrm{M}$ an, and Cybernetics Magazine, 6(2), 1048 (2020).

12. Merzban, H., Mahmoud Elbayoumi. Efficient solution of Otsu multilevel image thresholding: A comparative study. Expert Systems with Applications, 116, 299-309, (2019).

13. Saha, Punam K., Felix W. W ehrli, Bryon R. Fuzzy distance transform: theory, algorithms, and applications. Computer $V$ ision and Image Understanding 86(3), 171-190, (2002).

14. Chen $\mathbf{H}$. Effects of bedding orientation on the failure pattern and acoustic emission activity of shale under uniaxial compression. Geomechanics and Geophysics for Geo-Energy and GeoResources 7(1), 1-17 (2021).

\section{СПИСОК ЛИТЕРАТУРЫ}

1. Verstrynge E. A review on acoustic emission monitoring for damage detection in masonry structures. Construction and B uilding M aterials, 268, 121089 (2021).

2. Gholizadeh S, Baharudin, B. A review of the application of acoustic emission technique in engineering. Structural Engineering \& Mechanics, 54, 1075-1095 (2015).

3. ГОСТ-Р 52727, Техническая диагностика. Диагностика методом акустической эмиссии. Общие требования. - 2007.

4. Agletdinov E., M erson D., Vinogradov A. A new method of low amplitude signal detection and its application in acoustic emission. A pplied Sciences, 10, 73 (2020).

5. Pomponi E.; Vinogradov A. A real-time approach to acoustic emission clustering. Mech. Syst. Sig. Process. 40, 791-804 (2013). 
6. Kattis S. Noesis-A dvanced Data A nalysis, Pattern Recognition \& Neural Networks Software for Acoustic Emission Applications. Kolloquium Schallemission, Statusberichte zur Entwicklung und A nwendung der Schallemissionsanalyse, 910 (2017).

7. Kats V., Volkov A. Features extraction from non-destructive testing data in cyberphysical monitoring system of construction facilities. Journal of Physics: Conference Series, 1425, 012149 (2019)

8. Kats V. Structural health monitoring system of construction facilities: enhanced training approach. Journal of Physics: Conference Series, 1694(1) (2020)

9. Giannakopoulos T., Pikrakis A. Introduction to Audio Analysis - A MATLAB Approach. Elsevier Ltd., 262 (2014).

10. Wang $\mathbf{X u}, \mathbf{Y}$ usheng $\mathbf{X} \mathbf{u}, A \mathrm{n}$ improved index for clustering validation based on Silhouette index and Calinski-Harabasz

Vladislav A. Kats. PhD student of the department of Informational technology, systems and automatization in construction of the National Research Moscow State University of Civil Engineering; 129337, Russia, Moscow, Yaroslavskoe shosse, 26. E-mail: vladislavkats1894@gmail.com

Liubov A. Adamtsevich. Candidate of Technical Sciences, Associate Professor, A ssociate Professor of the department of Informational technology, systems and automatization in construction of the $\mathrm{N}$ ational Research M oscow State University of Civil Engineering; 129337, Russia, M oscow, Y aroslavskoe shosse, 26. E-mail: A damtsevichLA@mgsu.ru. index. IOP Conference Series: Materials Science and Engineering, 569(5) (2019).

11. K umar D., J ames C. V isual approaches for exploratory data analysis: A survey of the visual assessment of clustering tendency (vat) family of algorithms. IEEE Systems, $M$ an, and Cybernetics Magazine, 6(2), 1048 (2020).

12. Merzban, H., Mahmoud Elbayoumi. Efficient solution of Otsu multilevel image thresholding: A comparative study. Expert Systems with Applications, 116, 299-309, (2019).

13. Saha, Punam K., Felix W. W ehrli, Bryon R. Fuzzy distance transform: theory, algorithms, and applications. Computer $V$ ision and Image Understanding 86(3), 171-190, (2002).

14. Chen H. Effects of bedding orientation on the failure pattern and acoustic emission activity of shale under uniaxial compression. Geomechanics and Geophysics for Geo-Energy and GeoResources 7(1), 1-17 (2021).

Кач Владислав Анатольевич. Аспирант кафедры Информационных систем, технологий и автоматизации в строительстве Национального исследовательского Московского государственного строительного университета, 129337, Москва, Ярославское ш., д. 26, e-mail: vladislavkats1894@gmail.com

Адамџевич Любовь Андреевна, кандидат технических наук, доцент, доцент кафедры Информационных систем, технологий и автоматизации в строительстве Национального исследовательского Московского государственного строительного университета, 129337, Москва, Ярославское ш. ,д.26; тел. +7495-28749-14 доб.30-42, e-mail: A damtsevichLA @mgsu.ru ; ORCID: 0000-0002-5843-0076M 